\title{
Effect of cooling rate on the microstructure and mechanical properties of a low-carbon low-alloyed steel
}

\author{
Hongcai Wang ${ }^{1, *}$ (1) Lijie Cao ${ }^{1}$, Yujiao $\mathrm{Li}^{2}$, Mike Schneider ${ }^{1}$, Eric Detemple ${ }^{3}$, and \\ Gunther Eggeler $^{1}$ \\ ${ }^{1}$ Institute for Materials, Ruhr-Universität Bochum, 44801 Bochum, Germany \\ ${ }^{2}$ ZGH, Ruhr-Universität Bochum, 44801 Bochum, Germany \\ ${ }^{3}$ Department of Heavy Plate Research, AG Der Dillinger Hüttenwerke, 66763 Saar, Germany
}

Received: 14 December 2020

Accepted: 25 February 2021

Published online:

12 March 2021

(C) The Author(s) 2021

\begin{abstract}
Heavy plate steels with bainitic microstructures are widely used in industry due to their good combination of strength and toughness. However, obtaining optimal mechanical properties is often challenging due to the complex bainitic microstructures and multiple phase constitutions caused by different cooling rates through the plate thickness. Here, both conventional and advanced microstructural characterization techniques which bridge the meso- and atomicscales were applied to investigate how microstructure/mechanical propertyrelationships of a low-carbon low-alloyed steel are affected by phase transformations during continuous cooling. Mechanical tests show that the yield strength increases monotonically when cooling rates increase up to $90 \mathrm{~K} / \mathrm{s}$. The present study shows that this is associated with a decrease in the volume fraction of polygonal ferrite $(\mathrm{PF})$ and a refinement of the substructure of degenerated upper bainite (DUB). The fine DUB substructures feature C-rich retained austenite/martensite-austenite (RA/M-A) constitutes which decorate the elongated micrograin boundaries in ferrite. A further increase in strength is observed when needle-shaped cementite precipitates form during water quenching within elongated micrograins. Pure martensite islands on the elongated micrograin boundaries lead to a decreased ductility. The implications for thick section plate processing are discussed based on the findings of the present work.
\end{abstract}

Handling Editor: Megumi Kawasaki.

Address correspondence to E-mail: hongcai.wang@rub.de 


\section{Introduction}

Many mechanical and civil engineering applications rely on large components which are made of heavy plate steels. Examples are pressure vessels, bridges, ships and offshore platforms [1-6]. These components typically operate under severe conditions and require optimized strength and toughness. For these two key properties, they rely on the bainitic microstructure of steels [1, 2, 6-8]. A characteristic feature of thick section components is a microstructure which is not homogeneous throughout the cross section, because during heat treatments surface areas cool faster than the interior parts [9-13]. Therefore, it is crucial to establish combinations of microstructures across a thick section plate which provide the best overall properties. A pre-requisite for this type of optimization is an in-depth understanding of how microstructures evolve when materials are continuously cooled at different rates. Most steel heat treatments start with a homogenization in the austenite regime. On cooling from the austenite regime, the microstructural evolution during the decomposition of austenite and/or its phase transformation into bainite or martensite manifests itself by thermal effects, which can be detected by differential thermal analysis (DTA) and differential scanning calorimetry (DSC) [14-18]. However, thermal analysis on its own cannot identify the micro- and sub-micrometer scale elementary processes which govern microstructural evolution. These processes can be very complex and depend strongly on small variations of chemical composition and heat treatment parameters. This is an aspect which renders low-alloyed bainitic steels particularly intriguing. In such steels, not only different types of carbides can precipitate, but moreover, precipitation can be entirely suppressed and retained austenite (RA) and martensite-austenite regions (M-A) dominate the microstructure [19-25]. In the present study, a low-carbon low-alloyed steel with a bainitic microstructure was investigated. The microstructures formed after different cooling rates and microstructural parameters that are beneficial for the mechanical properties were identified and documented. Mechanical properties were evaluated by hardness measurements and compression tests. Different bainitic microstructures were categorized base on SEM images. RA/M-A constitutes were identified by electron diffraction in TEM and they were accounted partly for the enhanced strength of the steel after fast cooling. APT is used to characterize the size, shape and chemical composition of the nanosized RA/M-A constitutes, thus providing complementary evidence of their existence. The influence of cooling rate on the compressive yield stress is documented and the results are discussed on a microstructural basis. Despite phase transformation and precipitation reactions in bainitic steel are not a new topic, and many isolated observations have been reported in the past, the novelty of the present work is related to the fact that it bridges the gap between basic materials science (phase transformation and precipitation processes in bainitic steels) and thick section plate steel technology. With the objective to contribute to a better understanding of microstructural evolution during cooling from the austenite regime at different rates, advanced characterization techniques are combined in a unique way to show which microstructures are to be expected in different positions of a thick section plate. We also contribute to the clarification of some of the misunderstandings associated with terminology, regarding elementary diffusionless and diffusion controlled transformation reactions during slow (inside of a thick plate) and fast (surface of thick plate) cooling from the austenite regime.

\section{Material and experiments}

\section{Steel grade and dilatometry}

The compositions of the low-alloyed steel investigated in the present work are given in Table 1 (ASTM grade A387-11-2). Cylindrical specimens (height: $8 \mathrm{~mm}$, diameter: $4 \mathrm{~mm}$ ) were thermally analyzed using a Bähr DIL-805A/D dilatometer (ASTM standard: E228-17 [26]). The specimens were heated from room temperature (RT) at a heating rate of $10 \mathrm{~K} / \mathrm{s}$ to $1223 \mathrm{~K}$. At $1223 \mathrm{~K}$, they were held for $1 \mathrm{~h}$ and

Table 1 Chemical compositions of the low-alloyed steel investigated in the present work. Concentrations are given in at. $\%$ and wt. $\%$ as indicated

\begin{tabular}{llllllll}
\hline Element & $\mathrm{C}$ & $\mathrm{Cr}$ & $\mathrm{Mo}$ & $\mathrm{Si}$ & $\mathrm{Mn}$ & $\mathrm{Ni}$ & $\mathrm{Fe}$ \\
\hline wt. \% & 0.13 & 1.40 & 0.58 & 0.53 & 0.58 & 0.18 & base \\
at. \% & 0.60 & 1.49 & 0.33 & 1.04 & 0.58 & 0.17 & base \\
\hline
\end{tabular}


subsequently cooled down to RT, applying cooling rates $(\beta)$ of $0.5,1,5,10$ and $30 \mathrm{~K} / \mathrm{s}$. One specimen was water quenched (WQ) outside the dilatometer, its cooling rate was approximately $90 \mathrm{~K} / \mathrm{s}$. During thermal analysis, the temperatures were controlled using K-type thermocouples spot-welded onto the sample surfaces.

During the dilatometric measurements, the change of specimen length $\Delta L$ was measured and related to the initial specimen length $L_{0}$. The thermal expansion coefficient $\alpha(T)$ was then obtained as the change of this ratio with temperature $T$ :

$\alpha(T)=\frac{d}{d T}\left(\frac{\Delta L}{L_{0}}\right)[K-1]$

\section{Hardness measurements and compression testing}

After cooling to RT, hardness testing was performed using a semi-automatic micro/macro hardness tester of type KB30 BVZ from KB Prüftechnik. The Vickers hardness was measured (standard diamond indenter, right pyramidal shape with a square base and $136^{\circ}$ angles between opposite faces) applying a load of $10 \mathrm{~kg}$ for $10 \mathrm{~s}$. The hardness of each sample was obtained as the average of 10 random indentations. A 2-mm minimum distance between two adjacent indents allowed to exclude effects associated with local work hardening around next neighbor indents. Constant strain rate compression testing on representative samples was performed at room temperature $(293 \mathrm{~K}, \mathrm{RT})$ imposing an engineering strain rate of $10^{-3} \mathrm{~s}^{-1}$ in a Zwick Roell XForce Z100 test rig. To minimize friction between the specimens and anvil, the surfaces of the cylindrical specimen (height: $8 \mathrm{~mm}$, diameter: $4 \mathrm{~mm}$ ) were lubricated using MoS2 as a greasing agent. The compression tests were terminated at a plastic strain of $25 \%$.

\section{Scanning and transmission electron microscopy (SEM and TEM)}

Thin foils for TEM studies were prepared from specimens subjected to the thermal analysis with different cooling rates. A detailed description of how TEM specimens were prepared and how TEM results were analyzed is given elsewhere $[27,28]$. Thin slices were cut from the heat-treated specimens and ground down to a thickness of $60 \mu \mathrm{m}$ with a final grinding mesh size of 4000\#. Thinning was performed using a Struers Tenupol-5. Good thinning conditions were obtained using an electrolyte consisting of $70 \mathrm{vol} . \%$ methanol and 20 vol.\% glycerine and 10 vol.\% perchloric acid at a temperature of $-11{ }^{\circ} \mathrm{C}$ and a voltage of $30 \pm 5 \mathrm{~V}$. The foils were examined in a TECNAI G2 F20 TEM equipped with a field emission gun operating at $200 \mathrm{kV}$ and an energy-dispersive spectroscopy (EDS) system from EDAX ${ }^{\circledR}$. The thicker (non-electron-transparent) part of the TEM foils was investigated in an SEM of type FEI Quanta 650, equipped with an EDAX-TSL EBSD system operating at a voltage of $30 \mathrm{kV}$. Secondary electron images were taken at a working distance of $10 \mathrm{~mm}$. Orientation imaging measurements were performed using the $70^{\circ}$ specimen tilt and a working distance of $15 \mathrm{~mm}$. EBSD [29] data were acquired on representative samples using a step size of $0.3 \mu \mathrm{m}$. The misorientations were determined by setting the grain boundary detection limit to $2^{\circ}$ and the results are presented in colorcoded maps.

\section{Atom probe tomography}

Needle-shaped APT specimens containing RA/M-A constitutes from the specimen cooled at $30 \mathrm{~K} / \mathrm{s}$ were prepared following the procedure described in reference [30] using a dual-beam focused ion beam (FIB, FEI Helios G4 CX). These specimens were first cut out from the thicker parts of the TEM specimens and then FIB milled into a needle-like tip with a tip radius smaller than $50 \mathrm{~nm}$ using. APT investigations were performed using a local electrode atom probe (LEAP $5000 \mathrm{~h}$, Cameca Instruments) operating in voltage mode at $70 \mathrm{~K}$, with a pulse fraction of $20 \%$, a pulse repetition rate of $200 \mathrm{kHz}$, and a detection rate of 0.01 atoms per pulse. The APT data were reconstructed and analyzed using the commercial IVAS 3.8.4 software.

\section{Results}

\section{Dilatometric analysis}

In Fig. 1, we present the results from the dilatometric analysis. Figure 1a shows how the measured thermal strain $\Delta L / L_{0}$ changes with temperature for different cooling rates $(\beta)$. The associated dependence of the true thermal expansion coefficient $\alpha(T)$ is presented 
Figure 1 Results from thermal analysis obtained at cooling rates $\beta$ ranging from 0.5 to $30 \mathrm{~K} / \mathrm{s}$ (see color coding). a Thermal expansion as a function of temperature.

b Associated thermal expansion coefficient $\alpha(T)$ as a function of temperature. The peak temperatures $\mathrm{P}_{\mathrm{H}}$ (slow cooling rates) and $\mathrm{P}_{\mathrm{L}}$ (all cooing rates) are listed in the inset table.
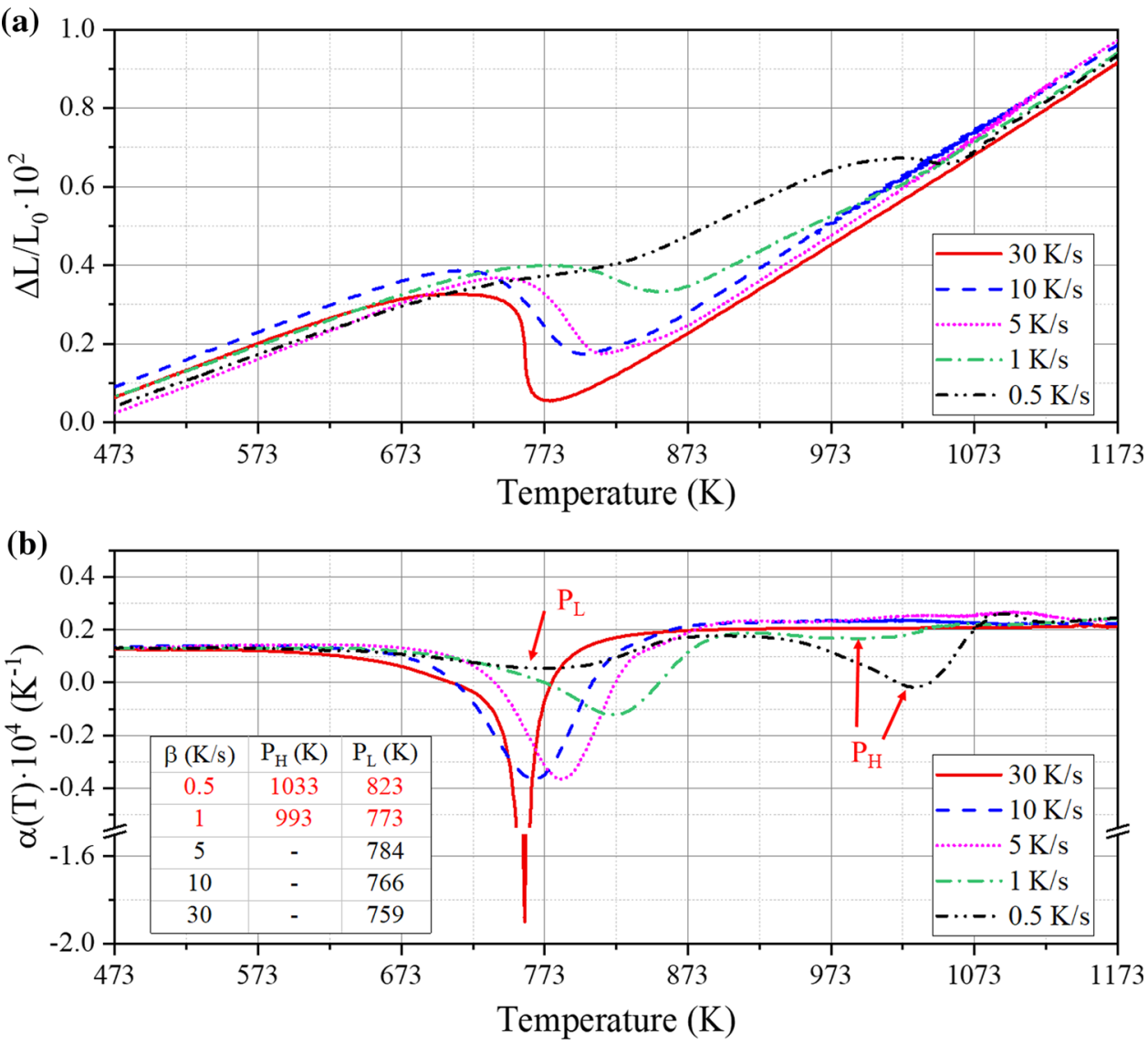

in Fig. 1b. For lower cooling rates $(\beta=0.5$ or $1 \mathrm{~K} / \mathrm{s})$, the $\alpha(T)$ curves exhibit two distinct peaks (P), one at higher temperatures $\left(\mathrm{P}_{\mathrm{H}}\right)$ and another at lower temperatures $\left(P_{L}\right)$, Fig. $1 b$. At higher cooling rates $(\beta$ $\geq 5 \mathrm{~K} / \mathrm{s}$ ), only one peak, $\mathrm{PL}$, is observed. The variation of peak temperatures with $\beta$ is presented in the inset table of Fig. 1b. It can be seen, that both $\mathrm{P}_{\mathrm{H}}$ and $\mathrm{P}_{\mathrm{L}}$ decrease with increasing $\beta$ (comparing $\beta \leq 1 \mathrm{~K} / \mathrm{s}$ and $\beta \geq 5 \mathrm{~K} / \mathrm{s}$ separately).

\section{Mechanical properties}

Figure 2 shows the evolution of the mechanical properties with different cooling rates $\beta$. In Fig. $2 \mathrm{a}$, the hardness results of all specimens are shown as a function of the applied cooling rate $\beta$. It can be seen that the Vicker's hardness (HV10) increases by a factor of two (from $140 \mathrm{HV}$ up to $280 \mathrm{HV}$ ), when $\beta$ is increased from $0.5 \mathrm{~K} / \mathrm{s}$ to $10 \mathrm{~K} / \mathrm{s}$. The hardness value $(\sim 440 \mathrm{HV})$ after water quenching $(\beta \approx 90 \mathrm{~K} / \mathrm{s})$ is almost three times as high as that observed after the slowest cooling experiment $(\beta=0.5 \mathrm{~K} / \mathrm{s})$. For four representatives of cooling rates, compression tests were performed at room temperature. Figure $2 b$ shows the stress/strain data presented as engineering stress $(\sigma)$ vs. engineering strain $(\varepsilon)$ (same color coding as in Fig. $2 \mathrm{a}$ ). The $0.2 \%$ yield stresses $\left(\sigma_{0.2}\right)$ for each $\beta$ are given in the inset table of Fig. $2 b$. Figure $2 b$ reveals that $\sigma_{0.2}$ increases with increasing $\beta$. Up to accumulated strains well above $10 \%$, the stress strain curves show higher stress levels for higher cooling rates, Fig. $2 \mathrm{~b}$. For $\beta \leq 30 \mathrm{~K} / \mathrm{s}$ (red, blue and yellow graphs in Fig. $2 b$ ) the compression tests showed barreling. In contrast, after water quenching (WQ, green curve in Fig. 2b), the onset of shearing was observed at about $17 \%$. This caused the decrease in the apparent stress level (green curve) as compared to the specimen which was cooled at $\beta=30 \mathrm{~K} / \mathrm{s}$ (yellow curve).

\section{Microstructural features observed by SEM}

The average prior austenite grain size before continuous cooling measured from SEM micrographs using the linear interception method was $30 \pm 10 \mu \mathrm{m}$ [23]. Figure 3 compiles overview SEM micrographs at 
Figure 2 Mechanical properties of specimens subjected to different cooling rates $\beta$. a Increase in Vicker's hardness (HV10) with increasing cooling rates. $\mathbf{b}$ Increase in yield stress $\sigma_{0.2}$ and plastic stress levels with increase cooling rates. For details see text.
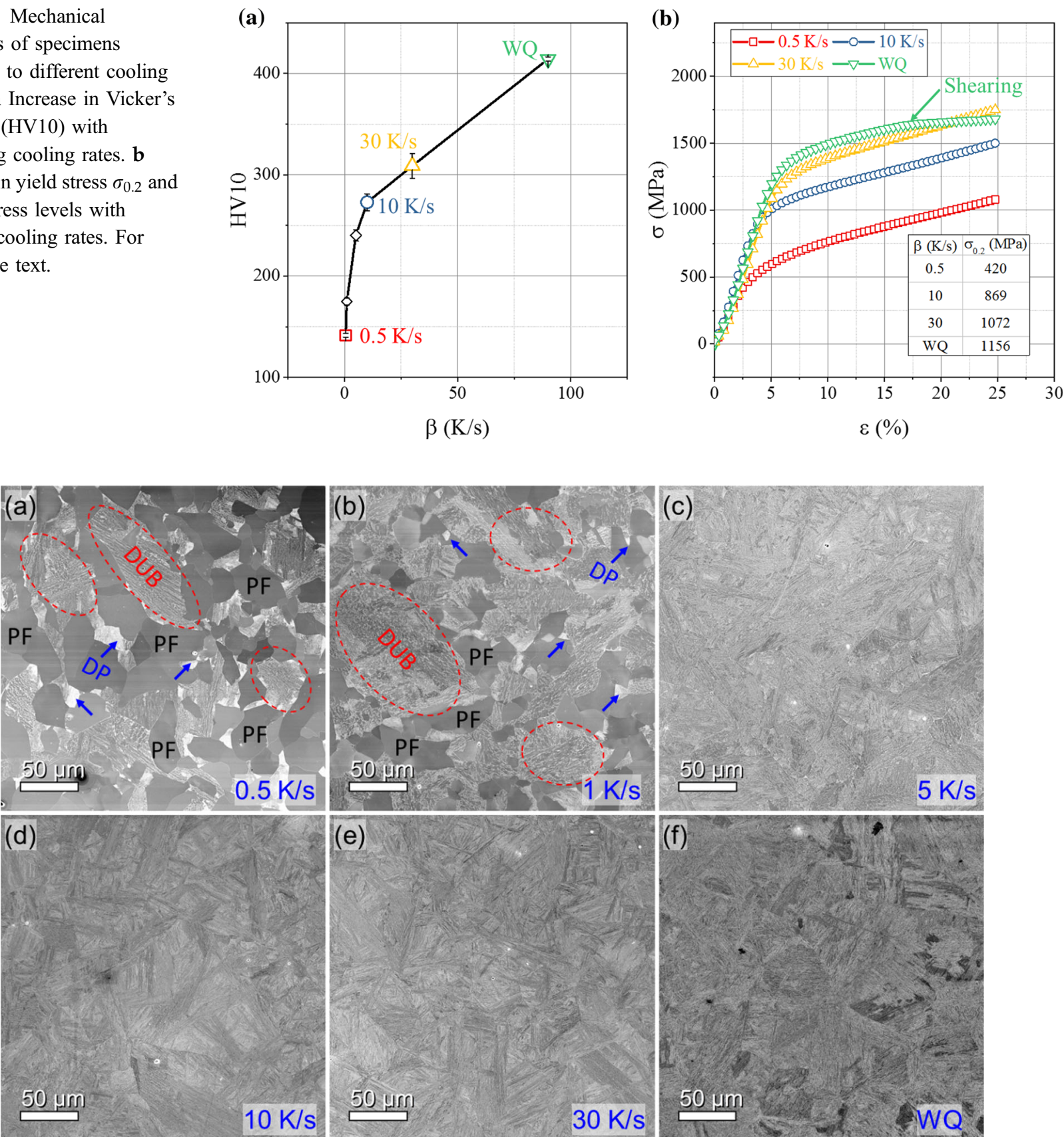

Figure 3 Secondary electron SEM micrographs showing microstructures after different cooling rates indicated in blue letters. Three types of local microstructures categorized as degenerated pearlite (DP), degenerated upper bainite (DUB) and

proper magnifications after different cooling rates. Materials subjected to slow cooling $(\beta=0.5$ and $1 \mathrm{~K} /$ s) show three types of local microstructures, Fig. 3a and $b$. In the present work, we refer to these microstructures as polygonal ferrite $(\mathrm{PF}$, featureless gray regions), degenerated pearlite (DP, arrow highlighted bright region) and degenerated upper bainite polygonal ferrite $(\mathrm{PF})$ highlighted in (a) $0.5 \mathrm{~K} / \mathrm{s}$ and (b) $1 \mathrm{~K} / \mathrm{s}$. Widmanstätten type of microstructure in specimens cooled at (c) $5 \mathrm{~K} / \mathrm{s}, \mathbf{d} 10 \mathrm{~K} / \mathrm{s}$, e $30 \mathrm{~K} / \mathrm{s}$ and $\mathbf{f}$ Water quenched. See text for details.

(DUB, ellipse highlighted regions with fine substructure). The designations polygonal ferrite, degenerated pearlite and degenerated upper bainite and their abbreviations PF, DP and DUB are used as proposed by Zajac et al. [19] and have been frequently adapted by many researchers such as $[11,31-34]$. Figures $3 a$ and $b$ show that the PF and DP 
volume fractions decrease as $\beta$ increases from $0.5 \mathrm{~K} / \mathrm{s}$ to $1 \mathrm{~K} / \mathrm{s}$. The fine-scale features of DP and DUB can be appreciated in the higher magnification SEM micrographs of Figs. $4 \mathrm{a}$ and $4 \mathrm{~b}(\beta=0.5)$. DP regions consist of a ferrite matrix with discontinuous cementite $(\theta)$ rodlets, Fig. 4a. DUB domains, on the other hand, consist of a ferrite matrix with elongated retained austenite/martensite-austenite (RA/M-A) films or blocky M-A islands, Fig. $4 \mathrm{~b}$.

In contrast, Widmanstätten type of microstructures as described in ref. [5] developed in all specimens cooled with $\beta \geq 5 \mathrm{~K} / \mathrm{s}$, which is difficult to discern in the low-mag SEM micrographs shown in Figs. 3c-f. Higher magnifications are required to show that the microstructure of specimens cooled at 5, 10 and $30 \mathrm{~K} / \mathrm{s}$ consists of ferrite with thin RA/M-A constitutes decorating the elongated micrograins (a general term for tiny grains with sub-micrometer dimensions, regardless of their misorientation angles between the neighboring grains/sub-grains [35]), Fig. 4c-e. This is the characteristic feature of DUB microstructures [17].
It is evident that the microstructure becomes finer as the cooling rates $\beta$ increase, i.e., both the widths of the elongated micrograins and the sizes of RA/M-A constitutes decrease. The blocky M-A type constitutes which are found in the microstructure of specimens with smaller $\beta$ (Fig. $4 \mathrm{~b}-\mathrm{d}$ ) disappear when specimens are cooled at $30 \mathrm{~K} / \mathrm{s}$ from the austenite regime, Fig. 4e. In contrast, in the water quenched specimen (WQ, $\beta \approx 90 \mathrm{~K} / \mathrm{s}$ ), the micrograin boundaries are decorated with small martensite islands instead of RA/M-A constitute. Moreover, fine precipitates (which will be identified as cementite $\theta$ in the following section) are present within the elongated ferritic micrograins, Fig. 4f. The microstructure can be categorized as autotempered martensite following the definition given in [5].

\section{TEM Analysis of Orientation Relationship}

TEM results from specimens cooled at $10,30 \mathrm{~K} / \mathrm{s}$ and by WQ are shown in Fig. 5. Figure $5 a$ and $b$ shows bright-field TEM (BF-TEM) images of microstructures
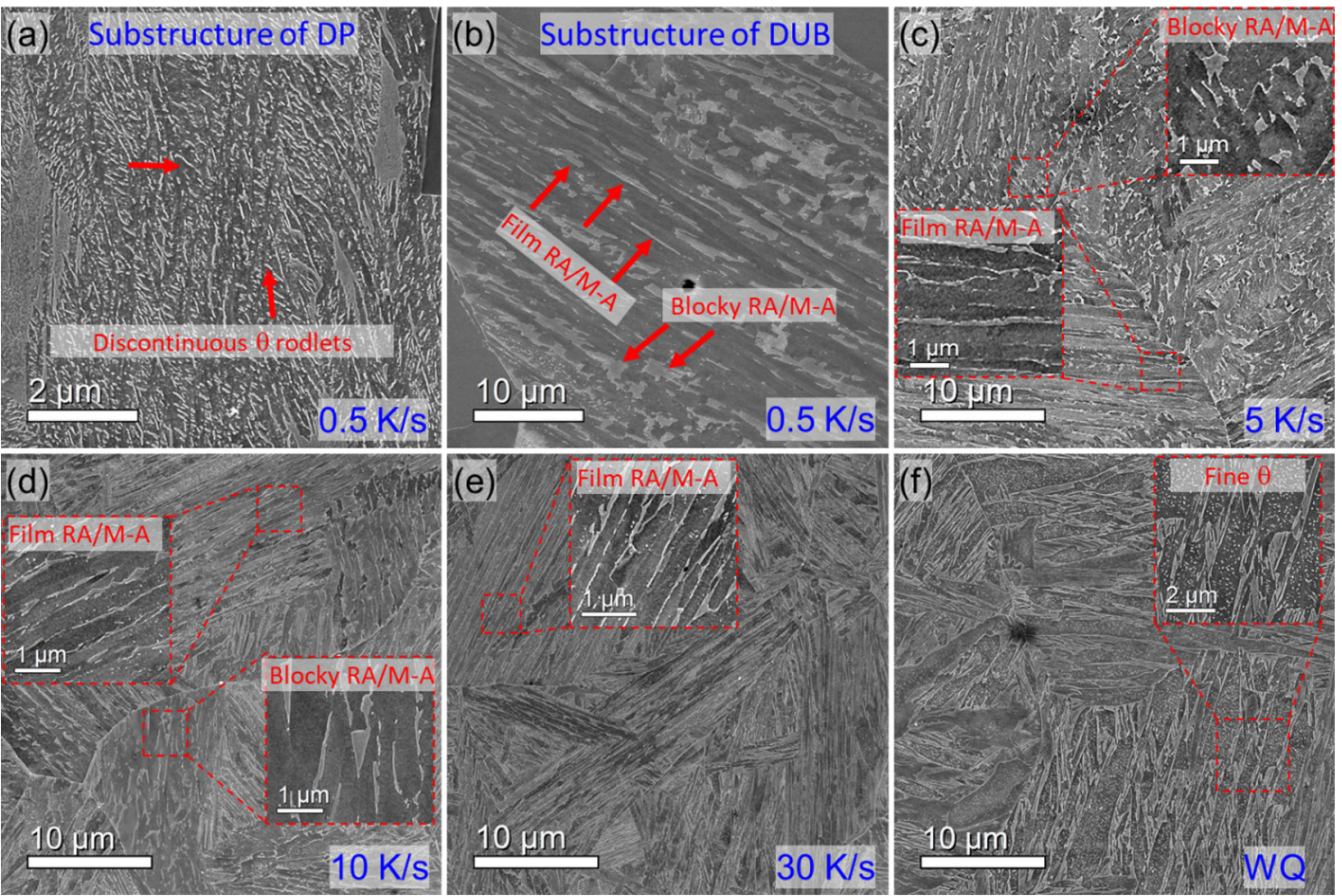

Figure 4 Higher magnification secondary electron SEM micrographs taken from specimens subjected to different cooling rates $\beta$. a Substructure of the DP (slow cooling, $0.5 \mathrm{~K} / \mathrm{s}$ ). b Substructure of DUB (slow cooling, $0.5 \mathrm{~K} / \mathrm{s}$ ). c and d Blocky and film RA/M-A constitutes in specimens cooled at 5 and $10 \mathrm{~K} / \mathrm{s}$, which are finer after faster cooling. e Absence of blocky constitute in specimen cooled at $30 \mathrm{~K} / \mathrm{s}$. f Fine cementite $(\theta)$ particles within elongated micrograins in the autotempered martensitic microstructure of the WQ specimen. See text for details. 

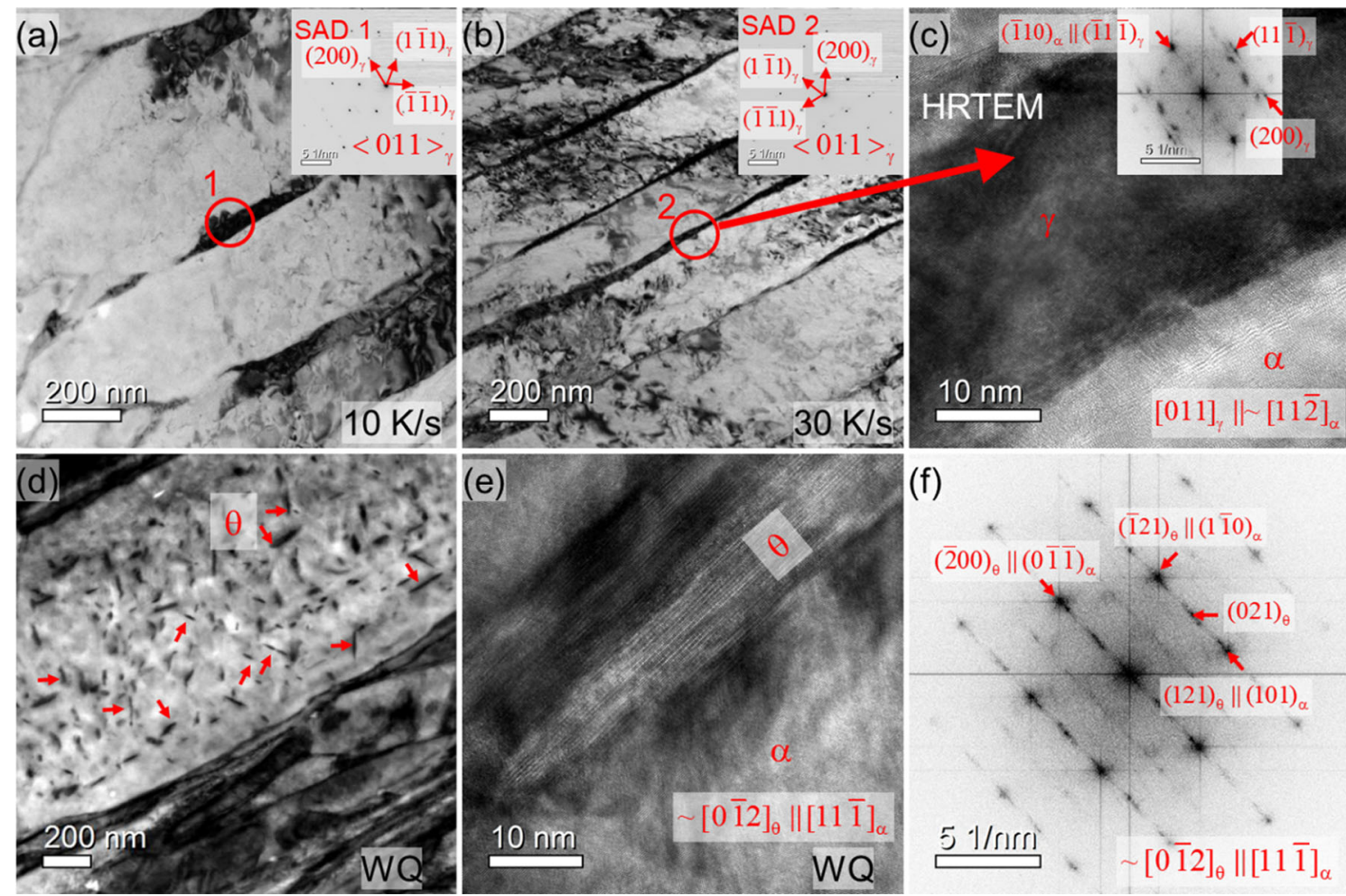

Figure 5 TEM analysis of orientation relationships between austenite, ferrite and carbides. a A BF-TEM micrograph together with a SAD pattern taken from the region highlighted by the red circle (" 1 ") in a specimen subjected to a cooling rate of $10 \mathrm{~K} / \mathrm{s}$. b A BF-TEM micrograph together with a SAD pattern taken from the highlighted region (red circle " 2 ") in a specimen cooled at $30 \mathrm{~K} / \mathrm{s}$. c A HRTEM micrograph taken from the highlighted region

from specimens cooled at 10 and $30 \mathrm{~K} / \mathrm{s}$, respectively. Selected area diffraction (SAD) patterns from the regions highlighted by red circles (insets in Fig. 5a and b) confirm that the dark thin films along the boundaries of the elongated micrograins represent retained austenite (RA). A high-resolution TEM (HRTEM) micrograph of the region highlighted by a red circle in Fig. 5b is presented in Fig. 5c. It shows an austenitic $\gamma$-film (central part of the image) with its $[011]_{\gamma}$ one axis parallel to the foil normal and parallel to $[11 \overline{2}]_{\alpha}$ zone axis of the $\alpha$-matrix region in the lower right of the micrograph. It is suggested that a Nishiyama-Wassermann (N-W) orientation relationship (OR) exists between the RA and the ferritic matrix, i.e., $[110]_{\gamma} / /[111]_{\alpha}$ and $(\overline{1} 11)_{\gamma} / /(\overline{1} 10)_{\alpha}$ (not explicitly shown here), even though it cannot be fully excluded that the OR corresponds to the classic KurdjumovSachs (K-S) relationship, which differs only by a relative rotation of $5.26^{\circ}$ about $[011]_{\alpha}$ [7]. The BF-TEM in (b) and its corresponding fast-fourier-transformation (FFT) shown as inset. d A BF-TEM micrograph showing needle-shaped $\theta$ particles within an elongated ferritic micrograin in the WQ specimen. e A HRTEM micrograph of a $\theta$ particle in the WQ specimen. f Corresponding FFT of (e), confirming that the needleshaped particles are cementite particles with specific ORs with respect to the ferrite matrix.

image in Fig. $5 d$ shows needle-shaped precipitates within one elongated ferritic micrograin in the WQ specimen. Due to their tiny size, their crystal structure can only be identified by HRTEM, Figs. 5e (image) and $\mathrm{f}$ (fast Fourier transform, FFT). The results indicate that these precipitates represent cementite (referred to as $\theta$, space group: Pbnm, $\mathrm{a}=0.453 \mathrm{~nm}$, $\mathrm{b}=0.509 \mathrm{~nm}, \mathrm{c}=0.674 \mathrm{~nm}, \alpha=\beta=\gamma=90^{\circ}$ [36]). There also exists an OR between these $\theta$ particles and the ferritic matrix. The ORs shown in Fig. 5e and $f$ are $(\overline{1} 21)_{\theta} / /(1 \overline{1} 0)_{\alpha^{\prime}} \quad(200)_{\theta} / /(011)_{\alpha^{\prime}} \quad$ and $\sim[0 \overline{1} 2]_{\theta} / /$ $[11 \overline{1}]_{\alpha}$, respectively. These correspond to one possible variant of the Bagaryatskii OR [37, 38]. The results presented in this section suggest that strict crystallographic ORs among austenite, ferrite and cementite accompany the decomposition of austenite. However, this is beyond the scope of the current work. Details regarding this aspect of the microstructural evolution can be found elsewhere [28, 39-41]. 


\section{Orientation imaging SEM analysis}

The SEM-EBSD technique was used to further characterize the boundary misorientation (MIS) of specimens cooled at $0.5,10,30 \mathrm{~K} / \mathrm{s}$ and by WQ $(\beta \approx 90 \mathrm{~K} /$ s). Figure $6 \mathrm{a}-\mathrm{d}$ shows histograms, where relative frequencies of MIS are presented. In addition, Fig. 6a-d contains image quality refined inverse pole figure maps (IPF + IQ) as insets. All histograms exhibit similar features, with two maxima at low (close to $\left.0^{\circ}\right)$ and high $\left(60^{\circ}\right.$ range) misorientation angles. The slowest cooling rate $(0.5 \mathrm{~K} / \mathrm{s})$ results in a microstructure, with a local frequency maximum at $45^{\circ}$ at the expense of $60^{\circ}$ MIS which is less frequent. Increasing the cooling rates to 10 and $30 \mathrm{~K} / \mathrm{s}$ leads to an increase in MIS in the angular range of $50-60^{\circ}$ and a simulataneous decrease in relative frequencies in other angular ranges, especially for $\mathrm{MIS}<20^{\circ}$, Fig. $6 \mathrm{~b}$ and c. In Fig. $6 \mathrm{~d}$, the WQ specimen exhibits significantly larger relative frequencies of low-angle MIS than all other samples. For high cooling rates $(30 \mathrm{~K} / \mathrm{s}$ and $\mathrm{WQ})$ an effort was made to distinguish between boundaries with MIS angles smaller than 20 (red) and larger than 50 (blue). The results are presented in Figs. 6e and $f$, where one can see that in specimen cooled at $30 \mathrm{~K} / \mathrm{s}$, there is a higher percentage of boundaries with higher misorientations (MIS $>50^{\circ}$, Fig. 6e: more blue boundaries) while boundaries with lower misoreintations (MIS $<20^{\circ}$, Fig. 6f: more red boundaries) prevail in the WQ sample.

\section{D APT analysis of local chemistry}

The 3-D quantitative elemental distributions in the RA/M-A constitutes observed in the specimen cooled at $30 \mathrm{~K} / \mathrm{s}$ were analyzed by APT. This specimen was chosen, because the orientation relationship between retained austenite and ferrite was determined by TEM analysis (see previous section). Figure 7a displays the $C$ atom map where a part of a RA film (of the type shown in Fig. 6c) is captured within the analyzed volume. The RA is identified by the region enclosed by the green-colored isoconcentration surfaces plotted for 3 at.\% C. Figure $7 b$ represents a magnified and rotated view from Fig. $7 \mathrm{a}$, where one of the $<011\rangle_{\alpha}$ poles points to the left (black arrow). The APT data suggest that lattice planes from the ferrite region (lower part of the image) continue into the austenite regime (upper part of the image). This is in agreement with the above HRTEM analysis, which revealed an N-W/K-S OR between the RA and the ferrite matrix. Figure 7c compiles 1-D concentration profiles of $\mathrm{C}, \mathrm{Cr}, \mathrm{Mn}, \mathrm{Si}$ and Mo measured along the black reference arrow in the region of interest (ROI) marked in Fig. 7a. It can be clearly seen, that in the $\mathrm{RA}$ regime, the $\mathrm{C}$ content increases to a maximum at 6 at.\%. This is one order of magnitude higher than the nominal $\mathrm{C}$ composition of 0.6 at. $\%$ in the ferrite matrix (Table 1). The concentration of the other elements ( $\mathrm{Cr}, \mathrm{Mn}, \mathrm{Si}$ and $\mathrm{Mo}$ ) does not change along the reference arrow, Fig. 7c.

The results presented in Fig. $7 \mathrm{~d}-\mathrm{f}$ were obtained from another analyzed region with an M-A constitute. In Fig. $7 \mathrm{~d}$, three zones can be distinguished. There is (i) a C-depleted ferrite zone (F) on the left, (ii) a $\mathrm{C}$-rich austenite zone with a homogenous $\mathrm{C}$ distribution in the middle and (iii) a C-rich martensite zone on the right with a heterogeneous distribution of C-atoms. Concentration profiles (proxigrams) of C and the other elements measured along the blue reference arrows 1 and 2 in Fig. $7 d$ are presented in Fig. $7 \mathrm{e}$ and $\mathrm{f}$, respectively. While the $\mathrm{C}$ content in the austenitic part of the M-A constitute (about 6 at. \%) is similar to that in the RA films, the martensitic part exhibits slightly lower $\mathrm{C}$ levels (close to 4 at. \%). Note that the $\mathrm{C}$ segregation levels exceed 8 at. $\%$ at the interface between austenitic and martensite within the M-A constitute, Fig. 7f. All the other alloying elements are homogeneously distributed within the analyzed volume.

\section{Discussion}

Using the state-of-the-art characterization methods, the results obtained in the present work show that cooling rates play a crucial role in the microstructural evolution of low-carbon low-alloyed steels, and this in turn influence the strength of materials by substructure refinement and precipitation hardening. In the following sections, we discuss such microstructural evolution with cooling rates, the mechanisms behind the microstructural evolution and its strengthening effect, and at last how this could provide insights for the processing of thick section plates. 

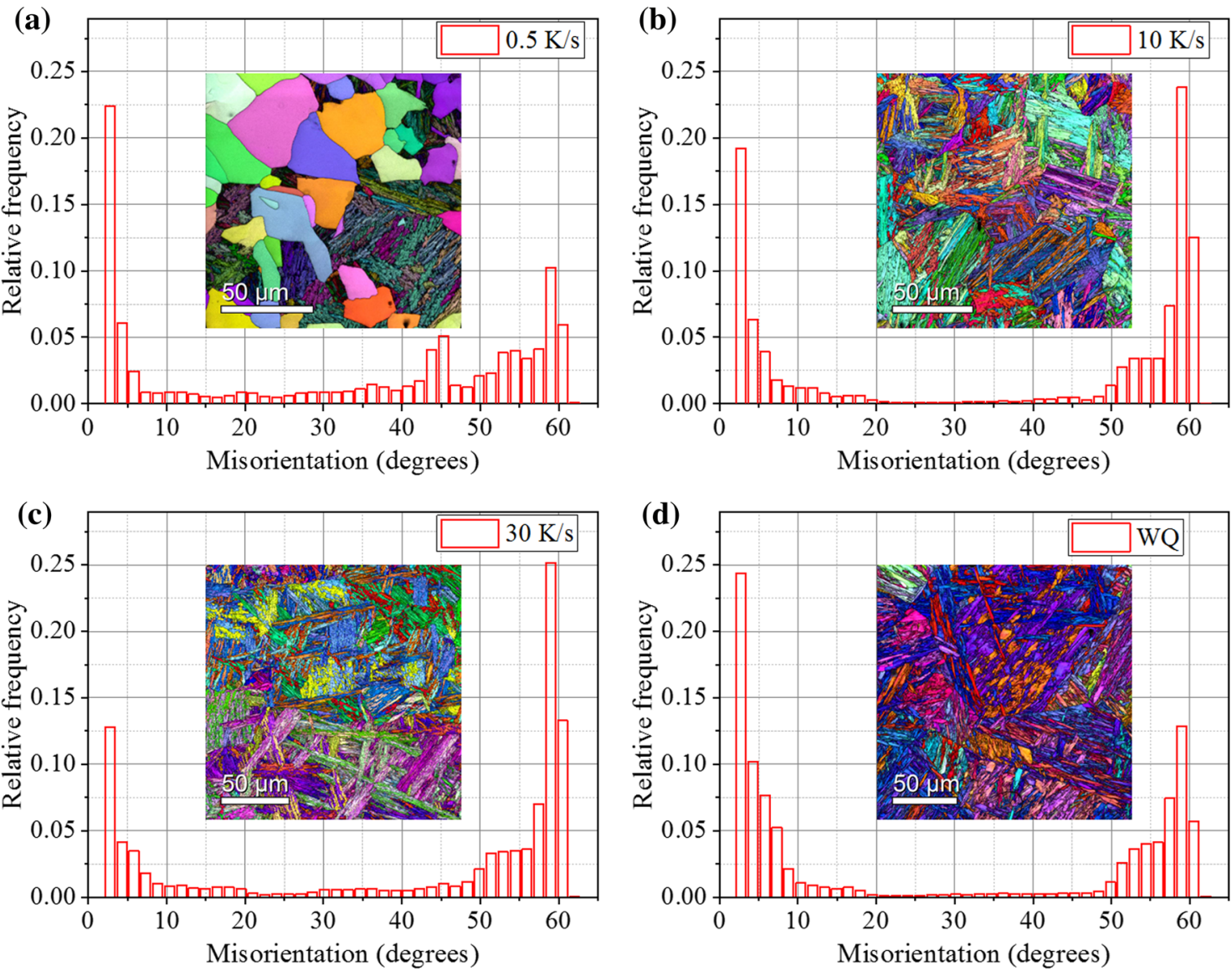

(e)

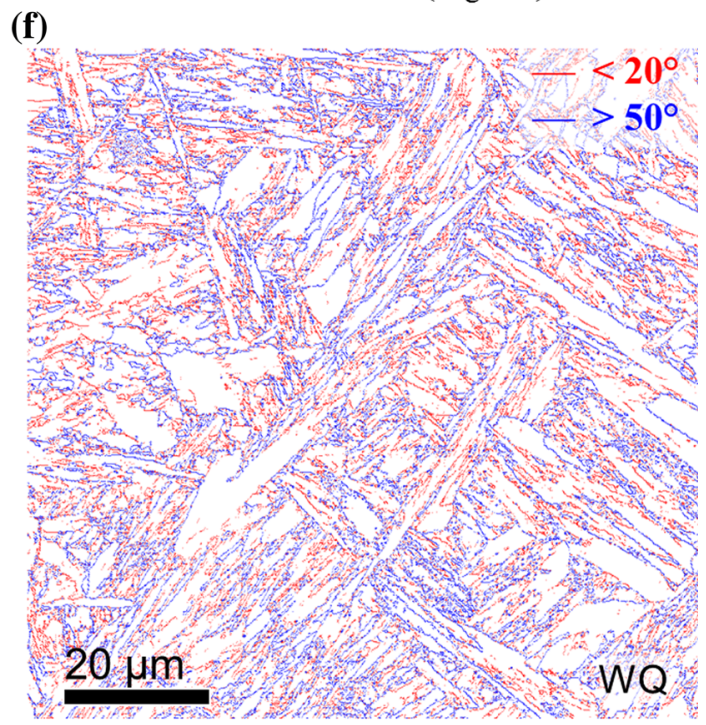

Figure 6 Results from orientation imaging SEM analysis. a-d: Histograms showing the relative frequencies of axis-angle rotation angles and IPF + IQ maps as insets. a $0.5 \mathrm{~K} / \mathrm{s}$. b $10 \mathrm{~K} / \mathrm{s}$. c $30 \mathrm{~K} / \mathrm{s}$. d WQ. e and f SEM-EBSD results for specimens cooled at $30 \mathrm{~K} / \mathrm{s}$

and by WQ showing boundaries with low (MIS $<20^{\circ}$, red) and high (MIS $>50^{\circ}$, blue) misorientation angles. Cooling rates: e $30 \mathrm{~K} / \mathrm{s}$ (more high angle boundaries, blue). f WQ (more lowangle boundaries, red). For details see text. 
Figure 7 Compilation of results from 3D APT local chemical analysis. a-c: APT tip volume containing a retained austenite/ferrite interface. a $\mathrm{C}$ isoconcentration surfaces at 3 at. $\% \mathrm{C}$ (green) in a RA film, with a high $\mathrm{C}$ concentration (red). b Rotated view of Fig. 7a, showing parallel lattice planes of RA and ferrite. ( $\mathrm{Fe}$ and $\mathrm{C}$ atoms displayed). c 1D concentration profiles measured along the black reference arrow inside the ROI in (a). $\mathbf{d}-\mathbf{f}$ : APT tip volume containing a ferrite/ retained austenite/martensite transition region. $\mathbf{d}$ Color coded presentation of atom distribution. Blue reference arrows: 1 across ferrite/ austenite interface, 2 across austenite/martensite interface. e Proxigramm concentration profile obtained along blue arrow 1. f Proxigramm concentration profile measured along blue arrow 2. For details see text.
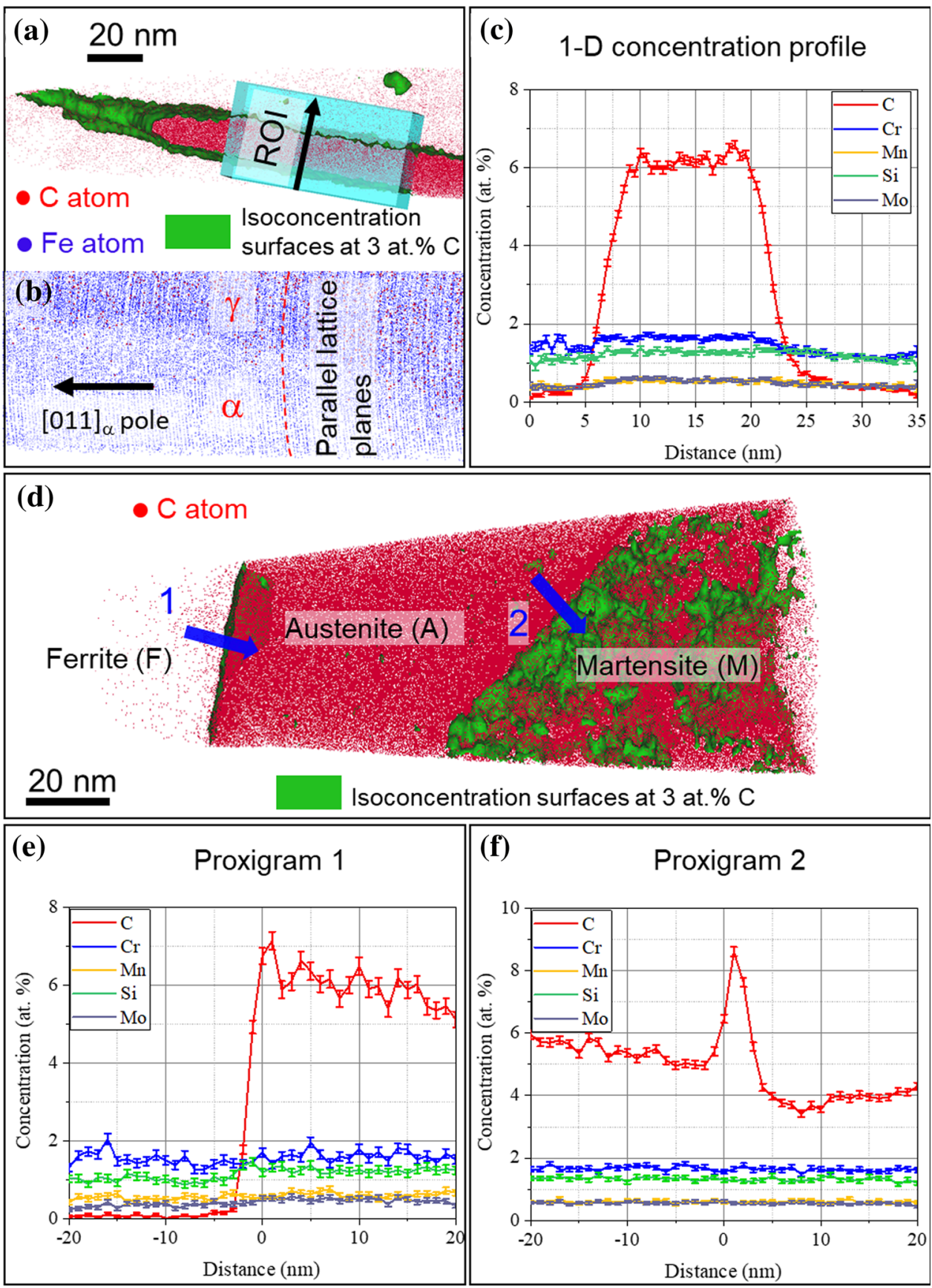

\section{Microstructural evolution and dilatometry}

Upon slow cooling $(0.5$ and $1 \mathrm{~K} / \mathrm{s})$ from the austenite regime, austenite decomposition starts with the formation of polygonal ferrite (PF). In the next step, the residual austenite transforms into degenerated pearlite (DP) and degenerated upper bainite (DUB), Figs. $3 a, b$ and Fig. 5a. Applying faster cooling rates $(5-30 \mathrm{~K} / \mathrm{s}), \mathrm{PF}$ and DP cannot form and the final microstructure only contains DUB (Figs. 3c-e,
Figs. 4c-e and Figs. 5b, c). These microstructural differences bear witness of the different thermodynamic and kinetic conditions which are also reflected in the dilatometric results shown in Fig. $1 \mathrm{~b}$. Two peaks, $\mathrm{P}_{\mathrm{H}}$ and $\mathrm{P}_{\mathrm{L}}$ characterize the $\alpha(T)$-curves at cooling rates of 0.5 and $1 \mathrm{~K} / \mathrm{s}$. It seems reasonable to assume that the $\mathrm{PH}$ peaks correspond to the formation of $\mathrm{PF}$, while the lower temperature peaks $\mathrm{P}_{\mathrm{L}}$ reflect the transformation from austenite to DP and DUB. The fraction of PF in the specimen cooled at 
$1 \mathrm{~K} / \mathrm{s}$ (Fig. 3b) is significantly lower than in that cooled at $0.5 \mathrm{~K} / \mathrm{s}$ (Fig. 3a), and thus the height of the $\mathrm{P}_{\mathrm{H}}$ for the specimen cooled at $1 \mathrm{~K} / \mathrm{s}$ is smaller than that of the specimen cooled at $0.5 \mathrm{~K} / \mathrm{s}$, Fig. 1b. For higher cooling rates $(5,10$ and $30 \mathrm{~K} / \mathrm{s})$, the high temperature peak $\mathrm{P}_{\mathrm{H}}$ is no longer observed and only the $\mathrm{P}_{\mathrm{L}}$ peak is found, Fig. $1 \mathrm{~b}$. This indicates the transformation from austenite to DUB.

\section{Mechanism of microstructural evolution}

Nanoscale partitioning of $\mathrm{C}$ accompanies all processes which have been discussed in the previous section. When PF forms during slow cooling in the two-phase austenite/ferrite region of the underlying quasi-binary phase diagram, it can only dissolve low $\mathrm{C}$ levels [5]. As a consequence, the $\mathrm{C}$ content of the residual austenite gradually increases. On further cooling at a low rate, the $\mathrm{C}$ content in retained austenite can reach the eutectoid concentration. DP is then formed by nucleation of cementite at ferrite/ austenite interfaces, followed by carbide-free ferrite layers enclosing the cementite particles [42]. Similar to what is known about lamellar pearlite, the formation of DP is controlled by diffusion. Due to the low C-diffusion rate, lamellar cementite cannot form $[42,43]$. When at low temperatures the DP formation can no longer occur, the remaining austenite eventually transforms to DUB. The formation of cementite is kinetically hindered in this temperature regime $[4,5]$.

At higher cooling rates higher $(5 \leq \beta \leq 30 \mathrm{~K} / \mathrm{s})$, the formation of PF is kinetically suppressed, high driving force build up and austenite can directly transform to the ferritic structure of elongated micrograins. The elongated micrograins contain thin films of retained austenite stabilized by $C$ [4]. This results in the formation of DUB microstructures. Figure 7 shows that the $C$ concentration in the RA is an order of magnitude higher (6 at.\%) than the nominal $C$ concentration in the steel (Table 1). It should be noted that low local $\mathrm{C}$ levels allow the corresponding region to transform into martensite, resulting in the formation of M-A constitutes, Figs. $7 \mathrm{~d}-\mathrm{f}$. C is more homogeneously distributed in the austenite while it shows a heterogeneous distribution in martensite, Fig. $7 \mathrm{~d}$. This is due to the fact that the internal structure of martensite often contains high densities of defects such as dislocations and mechanical twins, which represent the result of accommodation processes lowering the overall elastic strain energy associated with the transformation [44]. A lower solubility of $\mathrm{C}$ in the martensite as compared to that in the austenite in low-carbon steels results in significant segregation of C to theses defects [45], which can lead to the formation of the observed clusters even at low temperatures shown in Fig. $7 \mathrm{~d}$ [46].

\section{Implication for strengthening mechanisms}

The RA/M-A constitutes in the microstructures have a strong influence on the mechanical properties of low-alloyed steels [20, 24, 47-55]. A mechanism that describes the formation of blocky and film like RA/ M-A constitutes in DUB was proposed in Ref. [56]. In the current work, the best combination of mechanical properties are observed for the specimens cooled at $30 \mathrm{~K} / \mathrm{s}$, Fig. 2. There are a few factors which account for this finding. First, decreasing the volume fraction of soft PF increases the strength, as can be seen by comparing results from specimens with/without PF in Fig. 2. Second, since all samples were austenitized under the same conditions, the austenite grain sizes in all specimens prior to cooling are similar. Therefore, the possibility that in the present study prior austenite grain size has an effect on strength can be excluded. This is expected since the bainite sub-units after transformation are much smaller, resulting in an increase in hardness and yield stress. The elongated ferritic micrograins are typically between 5 and $50 \mu \mathrm{m}$ long and a few $\mu \mathrm{m}$ thick, Figs. 4 and 7. The boundaries that exist between adjacent elongated micrograins represent effective obstacles for dislocation motion. The thinner the micrograins, the smaller the mean free paths available for dislocation glide [7]. Third, when the cooling rate is high, there is not enough time for the nucleation of ferrite. Thus nuclei of ferrite will form rapidly when higher cooling rates enforce a stronger undercooling and higher associated driving forces. Large fractions of the austenite grain boundary areas will then be covered with nuclei [4]. Upon further lowering the temperature, the ferrite nuclei will grow into the austenite as Widmanstätten side-plates, which refine further with increasing cooling rates, Figs. 3, 4 and 5. Fourth, the presence of $\mathrm{M} / \mathrm{A}$ films on the boundaries of the elongated micrograins can act as additional barriers for dislocation motion [49]. Although the austenite becomes unstable during mechanical loading (which 
may cause reduction in toughness), good ductility can be maintained via the transformation induced plasticity (TRIP) effect [57-59]. However, the exact deformation behavior of the RA/M-A films during the compression test performed in the current study is still not clear. Finally, it is generally accepted that high angle grain boundaries are more effective dislocation obstacles than low-angle grain boundaries. However, the WQ specimen possesses the highest hardness and yield strength, although the percentage of high angle boundaries in the specimen cooled at $30 \mathrm{~K} / \mathrm{s}$ is much higher than in the WQ specimens, Figs. $6 \mathrm{e}$ and $\mathrm{f}$. Thus, the presence of fine cementite precipitates within the ferritic micrograins must have significantly contributed to the strength. Moreover, pure martensite on the ferritic micrograins also seems to be detrimental to the plastic deformation of the sample, as evidenced by the onset of sudden shear deformation during the compression test shown in Fig. 2.

\section{Implications for thick section plate processing}

The results presented in this work were motivated by the fact that during processing of thick section lowalloyed steel plates, different locations in the plate cool down at different rates (surface areas: fast, central regions: slow). We schematically illustrate some of our findings in Fig. 8. Clearly, our results only represent a first step towards a full description of the mechanical properties of a thick section plate material on a microstructural basis. Other material fields dealing with the mechanical properties of components with processing related heterogeneous microstructure deal with similar difficulties. While this has been known for quite some time [60,61], efforts to overcome the associated uncertainties have only started recently [11, 62-64]. Composite approaches will have to be used to progress this technologically important field. But the present study has also shown, that new microstructural insight can be gained, by addressing microstructural questions associated with process related microstructural heterogeneities. Further work is required to fully link local microstructural analysis to the mechanical properties on the macro-scale.

\section{Summary and conclusions}

In the present work, low-carbon low-alloyed steel specimens were cooled from the austenite regime. We investigated the influence of the continuous cooling rates on the hardness and on the compression yield stress, and their influence on microstructural evolution in order to rationalize local mechanical properties and local microstructures which form during heat treatments of thick section steels. Mechanical (hardness and compression) tests show that the strength increases monotonically with increasing cooling rates (up to $90 \mathrm{~K} / \mathrm{s}$ ). Based on the results obtained in the present work, the following conclusions can be drawn:

1. Upon slow cooling $(0.5$ and $1 \mathrm{~K} / \mathrm{s})$ from the austenite regime, the final microstructures consist of polygonal ferrite $(\mathrm{PF})$, degenerated pearlite (DP) and degenerated upper bainite (DUB). When the cooling rates are higher than $5 \mathrm{~K} / \mathrm{s}$, $\mathrm{PF}$ and DP do not form and the final microstructures contain only DUB.

2. The increase in strength with cooling rate up to $5 \mathrm{~K} / \mathrm{s}$ is mainly due to the decrease in the volume fraction of soft PF. A further increase in strength when cooling rates increase to $30 \mathrm{~K} / \mathrm{s}$ is attributed to even finer DUB substructures. Such fine substructures are characterized by elongated ferrite micrograins decorated with C-rich RA/M-A constitutes. The RA/M-A constitute at the micrograin boundaries may provide further strengthening by stabilizing boundaries and by preventing slip transmission between micrograins.

3. A further increase in the strength of the material can be achieved by forming needle-shaped cementite precipitates within ferritic micrograins by water quenching. However, when martensite islands replace RA/M-A constitutes on the elongated micrograin boundaries, the ductility of the material decreases.

4. The RA/M-A constitutes contain a high level of $\mathrm{C}$, which is one order of magnitude higher than the nominal $\mathrm{C}$ composition in the alloy.

5. The RA in the specimens cooled at $30 \mathrm{~K} / \mathrm{s}$ follows the Nishiyama-Wasserman (N-W) / KurdjumovSachs (K-S) OR with respect to the ferritic matrix. There is a Bagaryatskii OR between ferrite and cementite particles which precipitate during water quenching. 


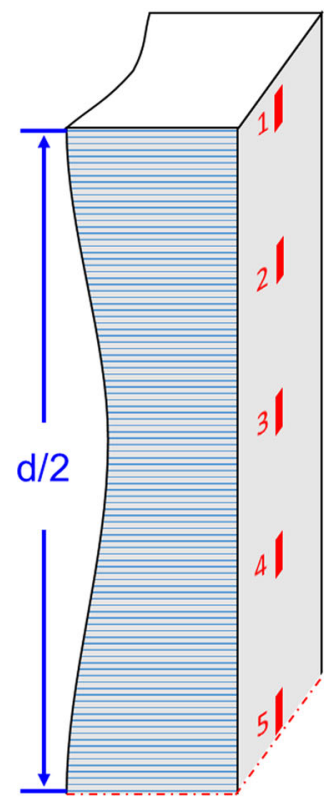

(a)

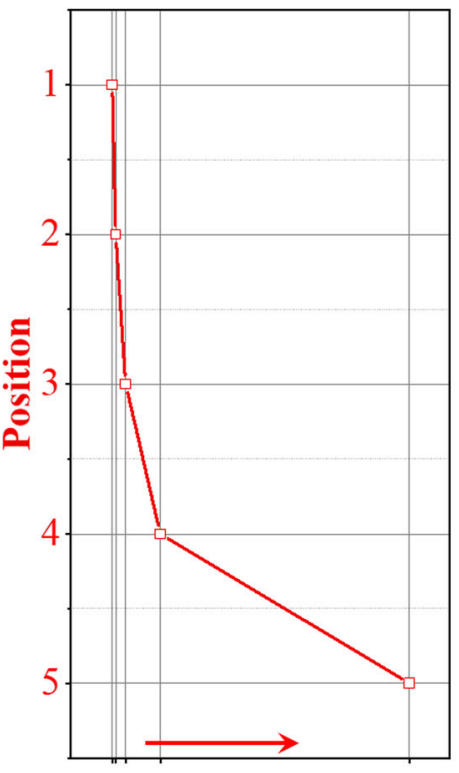

Time to reach $473 \mathrm{~K}$ (b)

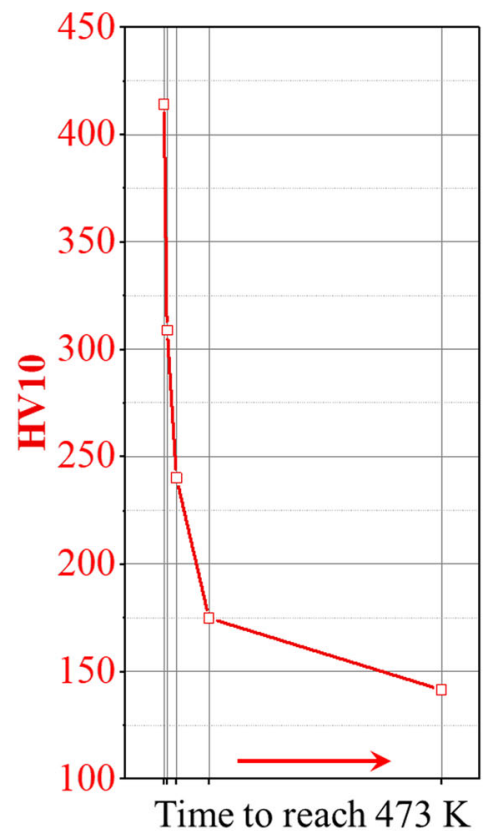

(c)

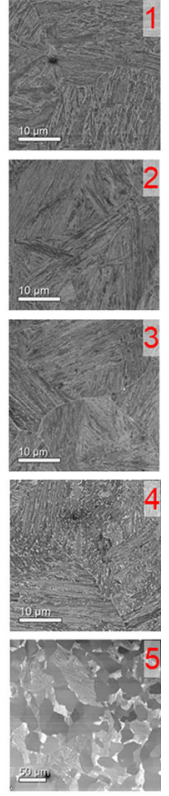

(d)
Figure 8 Schematic illustration of some of our findings. a Schematic illustration of a half cross section of a thick section plate (thickness: $d / 2$ ) with 5 positions from surface to center marked as $1-5$. $\mathbf{b}-\mathbf{d}$ Five experimental conditions and findings obtained in the present work, mimicking the hypothetical positions

6. The results presented in this work were motivated by the fact that during processing of thick section low-alloyed steel plates, different locations in the plate cool down at different rates (surface areas: fast, central regions: slow). Clearly, our results only represent a first step towards a full description of the mechanical properties of a thick section plate material on a microstructural basis. Further work is required to achieve this goal.

\section{Acknowledgements}

The authors are grateful to Mr. Klaus Bambauer for the help and fruitful discussion regarding the dilatometric measurements.

\section{Author contributions}

HW was involved in conceptualization, methodology, SEM and TEM, dilatometry, data curation, writing- original draft preparation; LC contributed to in a thick section plate as in (a). $\mathbf{b}$ Cooling rates indicated by the time required to reach $473 \mathrm{~K}\left(200^{\circ} \mathrm{C}\right)$. c Hardness corresponding to different positions across the thick section. $\mathbf{d}$ Microstructures (SEM micrographs) corresponding to different positions across the thick section.

EBSD investigation and analysis; YL was involved in APT investigation and analysis; MS contributed to compression tests and analysis; ED was involved in writing- reviewing and editing; GE contributed to supervision, writing- reviewing and editing.

\section{Funding}

Open Access funding enabled and organized by Projekt DEAL.

\section{Data availability}

The raw data used in the present study can be shared upon reasonable request to the authors.

Open Access This article is licensed under a Creative Commons Attribution 4.0 International License, which permits use, sharing, adaptation, distribution and reproduction in any medium or format, as long as you give appropriate credit to the original author(s) and the source, provide a link to the Creative Commons licence, and indicate if changes were 
made. The images or other third party material in this article are included in the article's Creative Commons licence, unless indicated otherwise in a credit line to the material. If material is not included in the article's Creative Commons licence and your intended use is not permitted by statutory regulation or exceeds the permitted use, you will need to obtain permission directly from the copyright holder. To view a copy of this licence, visit http://creativecommons.org/licen ses/by/4.0/.

\section{References}

[1] Leslie WC (1981) The physical metallurgy of steels. McGraw-Hill Book Company, New York

[2] Tamura I (1988) Thermomechanical processing of highstrength low-alloy steels. Butterworths, London, Boston

[3] ASM International (1990) ASM handbook Volume 1: properties and selection: irons, steels, and high-performance alloys. ASM International

[4] Porter DA, Easterling KE (1992) Phase transformations in metals and alloys, 2nd edn. Springer, US, Boston, MA

[5] Bhadeshia HKDH, Honeycombe RWK (2006) Steels: microstructure and properties. Butterworth-Heinemann, Oxford

[6] Krauss G (2015) Steels: processing, structure, and performance, 2nd edn. ASM International, Materials Park, Ohio

[7] Bhadeshia HKDH (2001) Bainite in steels: transformations, microstructure and properties, 2nd edn. IOM Communications, London

[8] Reynolds WT Jr (2001) Bainite. Encyclopedia of materials: science and technology, 2nd edn. Elsevier, Oxford, pp 453-457

[9] Hajeri KFA, Garcia CI, Hua M, Deardo AJ (2006) Particlestimulated nucleation of ferrite in heavy steel sections. ISIJ Int 46:1233-1240

[10] Capdevila C, García-Mateo C, Chao J, Caballero FG (2009) Advanced vanadium alloyed steel for heavy product applications. Mater Sci Technol 25:1383-1386

[11] $\mathrm{Hu}$ J, Du L-X, Xie $\mathrm{H}$ et al (2014) Microstructure and mechanical properties of TMCP heavy plate microalloyed steel. Mater Sci Eng A 607:122-131

[12] Xie B-S, Cai Q-W, Yun Y et al (2017) Development of high strength ultra-heavy plate processed with gradient temperature rolling, intercritical quenching and tempering. Mater Sci Eng A 680:454-468

[13] Zhang J, Xin W, Luo G et al (2018) Effect of the simulated and pilot-scaled thermomechanical processes on the microstructure, precipitates and mechanical properties of V-N alloyed steel. ISIJ Int 58:1883-1892

[14] Yang JR, Bhadeshia HKDH (1991) Continuous heating transformation of bainite to austenite. Mater Sci Eng A 131:99-113

[15] Kuzucu V, Aksoy M, Korkut MH, Yildirim MM (1997) The effect of niobium on the microstructure of ferritic stainless steel. Mater Sci Eng A 230:75-80

[16] Zhao L, Kop TA, Rolin V et al (2002) Quantitative dilatometric analysis of intercritical annealing in a low-silicon TRIP steel. J Mater Sci 37:1585-1591. https://doi.org/10. 1023/A:1014941424093

[17] Gojić M, Sućeska M, Rajić M (2004) Thermal analysis of low alloy Cr-Mo steel. J Therm Anal Calorim 75:947-956

[18] Gazda A (2010) Analysis of decomposition processes of ausferrite in copper-nickel austempered ductile iron. J Therm Anal Calorim 102:923-930

[19] Zajac S, Schwinn V, Tacke K-h (2005) Characterisation and quantification of complex bainitic microstructures in high and ultra-high strength linepipe steels. Mater Sci Forum 500-501:387-394

[20] Lan L, Qiu C, Zhao D et al (2012) Analysis of martensiteaustenite constituent and its effect on toughness in submerged arc welded joint of low carbon bainitic steel. J Mater Sci 47:4732-4742. https://doi.org/10.1007/s10853-012-634 6-x

[21] Terasaki H, Komizo Y (2013) Correlation between the microstructural development of bainitic ferrite and the characteristics of martensite-austenite constituent. Metall Mat Trans A 44:5289-5293

[22] Ojha S, Mishra NS, Jha BK (2015) Effect of cooling rate on the microstructure and mechanical properties of a C-Mn-CrB steel. Bull Mater Sci 38:531-536

[23] Wang H, Somsen C, Li Y et al (2019) Effect of Nb on improving the impact toughness of Mo-containing low-alloyed steels. J Mater Sci 54:7307-7321. https://doi.org/10. 1007/s10853-019-03374-2

[24] Lu Y, Yang J, Xu J et al (2019) Microstructure and mechanical properties of a low-carbon HDQ\&P steel. Heat Treat Surf Eng 1:87-96

[25] Liang G, Tan Q, Liu Y et al (2021) Effect of cooling rate on microstructure and mechanical properties of a low-carbon low-alloy steel. J Mater Sci 56:3995-4005. https://doi.org/ $10.1007 / \mathrm{s} 10853-020-05483-9$

[26] ASTM E228-17 (2017) Test method for linear thermal expansion of solid materials with a push-rod dilatometer. doi: https://doi.org/10.1520/E0228-17

[27] Wang H, Somsen C, Eggeler G, Detemple E (2018) Carbide types in an advanced microalloyed bainitic/ferritic $\mathrm{Cr}-\mathrm{Mo}$ 
Steel - TEM observations and thermodynamic calculations. Materwiss Werksttech 49:726-740

[28] Wang H (2018) Ex situ and in situ TEM investigations of carbide precipitation in a $10 \mathrm{Cr}$ martensitic steel. J Mater Sci 53:7845-7856. https://doi.org/10.1007/s10853-018-2075-0

[29] Schwartz AJ, Kumar M, Adams BL, Field DP (2009) Electron backscatter diffraction in materials science. Springer, US, Boston, MA

[30] Saxey DW, Cairney JM, McGrouther D et al (2007) Atom probe specimen fabrication methods using a dual FIB/SEM. Ultramicroscopy 107:756-760

[31] Kantor MM, Vorkachev KG (2017) EBSD investigation of continuously cooled microstructures in low carbon low alloy ferrite-pearlite steel. Sci Adv Mater 9:1968-1972

[32] Dey I, Chandra S, Saha R, Ghosh SK (2018) Effect of Nb micro-alloying on microstructure and properties of thermomechanically processed high carbon pearlitic steel. Mater Charact 140:45-54

[33] Xu Z, Ding Z, Liang B, Li H (2020) The analysis for morphological evolution and crystallography of degenerate pearlite in $100 \mathrm{Mn} 13$ steel. Materialwiss Werkstofftech 51:1251-1257

[34] Müller M, Britz D, Ulrich L et al (2020) Classification of bainitic structures using textural parameters and machine learning techniques. Metals 10:630

[35] Peŝickka J, Dronhofer A, Eggeler G (2004) Free dislocations and boundary dislocations in tempered martensite ferritic steels. Mater Sci Eng A 387-389:176-180

[36] (2020) FIZ Karlsruhe ICSD. https://icsd.fiz-karlsruhe.de. Accessed 24 Mar 2020

[37] Zhang M-X, Kelly PM (1998) Crystallography of spheroidite and tempered martensite. Acta Mater 46:4081-4091

[38] Guziewski M, Coleman SP, Weinberger CR (2016) Atomistic investigation into the atomic structure and energetics of the ferrite-cementite interface: the Bagaryatskii orientation. Acta Mater 119:184-192

[39] Zhang X, Hickel T, Rogal J et al (2015) Structural transformations among austenite, ferrite and cementite in $\mathrm{Fe}-\mathrm{C}$ alloys: a unified theory based on ab initio simulations. Acta Mater 99:281-289

[40] Zhang X, Hickel T, Rogal J, Neugebauer J (2016) Interplay between interstitial displacement and displacive lattice transformations. Phys Rev B 94:104109

[41] Wang H, Zhang X, Yan D et al (2018) Interface dominated cooperative nanoprecipitation in interstitial alloys. Nat Commun 9:4017

[42] Ohmori Y, Ohtani H, Kunitake T (1971) The bainite in low carbon low alloy high strength steels. Tetsu-to-Hagane 57:1690-1705
[43] Shanmugam S, Ramisetti NK, Misra RDK et al (2008) Microstructure and high strength-toughness combination of a new $700 \mathrm{MPa} \mathrm{Nb}$-microalloyed pipeline steel. Mater Sci Eng A 478:26-37

[44] Bhadeshia HKDH, Wayman CM (2014) Phase transformations: nondiffusive. In: Laughlin DE, Hono K (eds) Physical metallurgy, 5th edn. Elsevier, Oxford, pp 1021-1072

[45] Zhang X, Wang H, Hickel T et al (2020) Mechanism of collective interstitial ordering in $\mathrm{Fe}-\mathrm{C}$ alloys. Nat Mater 19:1-6

[46] Miller MK, Beaven PA, Brenner SS, Smith GDW (1983) An atom probe study of the aging of iron- nickel- carbon martensite. MTA 14:1021-1024

[47] Thompson SW, Col DJV, Krauss G (1990) Continuous cooling transformations and microstructures in a low-carbon, high-strength low-alloy plate steel. MTA 21:1493-1507

[48] Ohtani H, Okaguchi S, Fujishiro Y, Ohmori Y (1990) Morphology and properties of low-carbon bainite. MTA 21:877-888

[49] Zhong Y, Xiao F, Zhang J et al (2006) In situ TEM study of the effect of $\mathrm{M} / \mathrm{A}$ films at grain boundaries on crack propagation in an ultra-fine acicular ferrite pipeline steel. Acta Mater 54:435-443

[50] Yakubtsov I, Zhang R, Boyd D (2011) Particularities of the formations of bainite and martensite/austenite phase in low carbon low alloy steels during continuous cooling. IJMR 102:504-512

[51] Lan L, Qiu C, Song H, Zhao D (2014) Correlation of martensite-austenite constituent and cleavage crack initiation in welding heat affected zone of low carbon bainitic steel. Mater Lett 125:86-88

[52] Maresca F, Kouznetsova VG, Geers MGD (2014) On the role of interlath retained austenite in the deformation of lath martensite. Model Simul Mater Sci Eng 22:045011

[53] Li CW, Han LZ, Luo XM et al (2016) Fine structure characterization of martensite/austenite constituent in low-carbon low-alloy steel by transmission electron forward scatter diffraction. J Microsc 264:252-258

[54] Hofer C, Bliznuk V, Verdiere A et al (2018) High-resolution characterization of the martensite-austenite constituent in a carbide-free bainitic steel. Mater Charact 144:182-190

[55] Pu SD, Turk A, Lenka S, Ooi SW (2019) Hydrogen desorption change after deformation of a bainitic steel with unstable retained austenite. Scripta Mater 170:38-42

[56] Qiao ZX, Liu YC, Yu LM, Gao ZM (2009) Formation mechanism of granular bainite in a $30 \mathrm{CrNi} 3 \mathrm{MoV}$ steel. J Alloy Compd 475:560-564

[57] Bhadeshia HKDH, Edmonds DV (1980) The mechanism of bainite formation in steels. Acta Metall 28:1265-1273 
[58] Abbasi E, Rainforth WM (2017) Microstructural evolution of $\mathrm{Nb}-\mathrm{V}-\mathrm{Mo}$ and $\mathrm{V}$ containing TRIP-assisted steels during thermomechanical processing. J Mater Sci Technol 33:311-320. https://doi.org/10.1016/j.jmst.2016.08.019

[59] Chen S-C, Wang Y-T, Lin Y-C et al (2019) Microstructure and mechanical behaviors of GPa-grade TRIP steels enabled by hot-rolling processes. Mater Sci Eng A 761:138005

[60] Hornbogen E (1985) Strength of alloys with heterogeneous microstructures. Czech J Phys 35:193-205

[61] Hornbogen E (1986) Description and wear of materials with heterogeneous and anisotropic microstructures. Wear 111:391-402
[62] Zhou T, Yu H, Wang S (2017) Microstructural characterization and mechanical properties across thickness of ultraheavy steel plate. Steel Res Int 88(12):1700132

[63] Wu P (2018) The effect of inhomogeneous microstructures on strength and fatigue properties of an $\mathrm{Al}-\mathrm{Cu}-\mathrm{Li}$ thick plate. Mater Sci Eng A 731:1-11

[64] Zeng X, Fan XG, Li HW et al (2020) Heterogeneous microstructure and mechanical property of thin-walled tubular part with cross inner ribs produced by flow forming. Mater Sci Eng A 790:139702

Publisher's Note Springer Nature remains neutral with regard to jurisdictional claims in published maps and institutional affiliations. 